\title{
Development of Interdisciplinary Lessons Integrating Science and Engineering in Heterogeneous Teams: Education Students' Attitudes
}

\author{
http://dx.doi.org/10.3991/ijep.v6i2.5683
}

\author{
A. Gero
}

Technion - Israel Institute of Technology, Haifa, Israel

\begin{abstract}
The course "Interdisciplinary Aspects in Science and Engineering Education" is a unique course designed to expose students of science and engineering education to the characteristics of interdisciplinary teaching and learning. The theoretical part of the course deals with the nature of science and engineering and the interaction between the two, various hierarchies describing the level of integration between disciplines, and possible strategies for developing interdisciplinary lessons. In the practical section, the participants develop, in heterogeneous teams of students from different academic backgrounds, an interdisciplinary lesson integrating science and engineering, and teach it to their peers. Using qualitative tools, the research described in this paper characterized the attitudes of 112 students towards developing an interdisciplinary lesson as part of a team. The findings indicate that the students identified both the difficulties involved in developing an interdisciplinary lesson as part of a team and the advantages inherent to teamwork. It was further found that the weight of the attitude component that recognized the contribution of teamwork to the development of interdisciplinary lessons was considerably higher than the weight of the component indicating the difficulties that involved teamwork.
\end{abstract}

Index Terms - Engineering education, heterogeneous teams, interdisciplinary education, science education, teacher training.

\section{INTRODUCTION}

Interdisciplinarity is the integration or synthesis of knowledge from various disciplines [1]. Recently, in view of the expectation that interdisciplinary learning will contribute to the development of higher-order thinking skills [2-3] and increase the motivation to study [4], numerous high-school courses integrating science and engineering have been developed. There are programs about avionics [5], other focus on electro-optics [6-7], robotics [8-9], information technology [10] or nanotechnology [11]. The programs vary in duration: from a limited number of meetings for outreach purposes $[5,7]$ to three-year programs ending with matriculation exams [6].

Alongside the benefits inherent to the aforementioned interdisciplinary programs, there are also fundamental challenges in developing and implementing such curricula. These challenges stem, inter alia, from the difficulty in developing a course which balances the interdisciplinary and the disciplinary elements [12], and the difficulty teachers teaching interdisciplinary courses have in coping with a field or with fields of knowledge they have not been trained to teach [13].

In 2010, considering the importance of interdisciplinary learning on one hand, and the difficulties inherent to interdisciplinary teaching on the other, a unique course designed to expose students of science and engineering education to the characteristics of interdisciplinary teaching and learning was developed by the Department of Education in Technology and Science, at the Technion - Israel Institute of Technology. The course "Interdisciplinary Aspects in Science and Engineering Education" included both theoretical and practical contents culminating in an interdisciplinary lesson each student was supposed to develop and teach his/her classmates. A study, which characterized attitudes towards interdisciplinary learning and teaching integrating science and engineering among sixteen students who participated in the course, was published [14]. The results of this study indicate that the students recognized the educational value of interdisciplinary learning as well as the difficulties accompanying this kind of teaching.

A fundamental change was made to the course in 2012. The essence of the change is that the interdisciplinary lesson, which is the core of the course, is developed and taught by a heterogeneous team of students, with various academic backgrounds, rather than by a single student. The change was implemented in light of the acknowledgment that modern work patterns are characterized by interdisciplinary teamwork [15], and that one of the most important conditions for the success of an interdisciplinary program is for it to be developed and taught by a heterogeneous team of teachers [12, 16-17]. Therefore, the intention was to allow students to practice working in a heterogeneous team at a relatively early stage, i.e., during the course of their studies, prior to them being certified as teachers.

The study described below characterized attitudes towards developing interdisciplinary lessons in heterogeneous teams among 112 students who had attended the course between 2012 and 2015. To the best of our knowledge, this is the first time a characterization of this sort has been implemented.

The paper opens with a description of the course "Interdisciplinary Aspects in Science and Engineering Education", followed by a presentation of the research objective and the chosen methodology. After describing the primary 
findings, a discussion is held and the conclusions are presented.

\section{COURSE DESCRIPTION}

The elective course "Interdisciplinary Aspects in Science and Engineering Education" is a two-hour weekly course designed for students of science and engineering education in the advanced stage of their undergraduate studies. During the course of their studies, these students specialize in one of the following tracks: engineering education (electrical engineering or mechanical engineering), science education (physics, chemistry, biology or computer sciences) or mathematics education. The course was designed to expose the students to the characteristics of interdisciplinary teaching and learning integrating science and engineering.

The first weeks of the course are dedicated to a discussion about the nature of science and engineering and the interaction between the two [18]. During this stage, criteria allowing distinction between science and engineering [19] are discussed, like for example, the driving factor (curiosity in science as opposed to necessity in engineering), aspiration (perfection in science as opposed to optimum in engineering) and the type of solution sought (a general solution in science as opposed to a specific solution in engineering). Later, classification methods for different disciplines and various hierarchies describing the level of integration between fields of knowledge are reviewed. For example, Piaget's hierarchy [20], which starts with multidisciplinarity (a presentation of a number of fields of knowledge with no attempt to integrate them), continues on to interdisciplinarity (integration between various fields of knowledge) and ends in transdisciplinarity (the highest level of integration, in which it is no longer possible to identify the components of the various fields it is based on). The theoretical section is sealed with a discussion about possible strategies for developing interdisciplinary lessons [21], like the use of a crossdisciplinary concept (e.g., linearity) or focusing on a system or a problem which requires knowledge from several fields (e.g., genetic engineering - is it ethical?).

At the beginning of the practical part, the students are asked to divide themselves, at their own discretion, into teams of two to four students, in such a way that the teams are heterogeneous and composed of students from various tracks of study. The team members are asked to develop a 45-minute lesson on an interdisciplinary topic of their choosing, which integrates science and engineering. The lesson is to be at a high-school or university level, without being restricted to a particular method of teaching. For the purpose of developing the lesson, the students may seek the assistance of the course faculty; however, the working procedures of the team are determined by the team members without faculty interference. Examples of interdisciplinary lessons developed as part of the course are provided in Appendix A. A description of an interdisciplinary lesson on the topic of Laser Rangefinders, which integrates physics and electrical engineering, can be found in Appendix B.

All the team members take part in the process of teaching the lesson. The rest of the students participate actively in the lesson, and simultaneously, fill out an appropriate evaluation form. In the form, each student is asked to identify the location of the lesson on the interdisciplinary hierarchy proposed by Piaget [20] and mentioned above.
In addition, if the lesson was indeed interdisciplinary - the student must determine the strategy the team implemented in order to develop the lesson in question. At the end of the lesson, the team members are required to submit a reflection report based on the impression they got and on the evaluation forms they received from their classmates. A summary discussion is held in class during the last course session.

The primary component of the course grade is derived from the lesson's interdisciplinary level. Failure to sufficiently reflect the integration of the various disciplines in the lesson - will compromise the grade. The team members' quality of teaching and the report written by them are also taken into consideration in determining the grade.

\section{RESEARCH GOAL AND METHODOLOGY}

The objective of the study was to characterize attitudes of students participating in the course towards developing an interdisciplinary lesson as part of a team.

The research population included 112 students who participated in the course (in its new format) between 2012 and 2015. It is important to note that the students were not exposed to interdisciplinary education prior to this course, and that they did not have prior experience in working (or learning) in a heterogeneous team. In addition, between 2012 and 2015, the format of the course (including the contents, the assignments and the composition of the final grade) and the teaching faculty did not change.

Since the study focused on characterizing students' attitudes, the constructivist-qualitative methodology [22] was chosen. Each student was asked to fill out an open-ended questionnaire at the end of the lesson taught by him/her as part of the team. The questionnaire is provided in Appendix C. In addition, in order to increase the trustworthiness of the findings, after the completion of the course, twelve semi-structured interviews were held with students, in eight of which, teams were interviewed, and in four, individual students. A sample of the interview questions appears in Appendix D.

The data underwent content analysis and were classified into categories. Rosenberg and Hovland's tricomponent attitude model [23] served as the theoretical framework for the qualitative analysis.

\section{FINDINGS}

An analysis of the findings indicates the presence of an affective component, a behavioral component and a cognitive component in students' attitudes. From the affective aspect, about one fifth (18.75\%) of the students answering the questionnaire thought that work in teams contributed to reinforcing their sense of self-confidence: "In a team you can rehearse the lesson [in front of the rest of the team members], and the rehearsals reinforce the sense of selfconfidence" (questionnaire).

From the behavioral aspect, approximately one quarter $(23.20 \%)$ of the students mentioned the inclination of the team members to attempt to place the most emphasis on the discipline they were familiar with at the expense of the other disciplines: "During the preparation [of the lesson] everyone tried to make more room for his or her own field of knowledge" (questionnaire).

The cognitive component in students' attitudes is more complex and includes reference to the difficulties in 
teamwork on one hand, the advantages inherent to it on the other, as well as insights in relation to teamwork. The students indicated two primary difficulties: about one third $(30.40 \%)$ of the students stated that they encountered difficulty in choosing an interdisciplinary topic which was agreed upon by all members of the team: "As a team it's difficult to pick a topic which interests everyone" (questionnaire), and approximately one quarter $(24.10 \%)$ of the students noted the difficulty in getting agreement from the team members regarding the contents of the lesson: "The greatest difficulty is deciding what to include in the lesson and what not to... sometimes one of the team members really likes a certain example, but someone else does not" (interview).

Alongside these difficulties, the students mentioned four advantages embodied in teamwork. About two thirds $(62.50 \%)$ of the students recognized the contribution of the team members in completing knowledge gaps, since each of them was well versed in a different field: "Everyone comes from a different field... each contributes his or her share... I [the student well versed in mechanical engineering] taught $B$. mechanical engineering and she [who was well versed in biology] taught me biology... that's an important benefit of teamwork" (interview). Approximately $40 \%$ of the answers noted the team's contribution to improving teaching skills: "I could use the team members to see whether I was explaining all the concepts I was using well, and if the examples I was giving were good examples" (questionnaire). A similar rate $(37.50 \%)$ of students mentioned the team's contribution to finding a mix that balanced the disciplinary and the interdisciplinary components of the lesson: "One can consult [the team] to ensure the topics do in fact integrate well... to see whether the proportion between the disciplinary and the interdisciplinary sections is appropriate" (interview). About one fifth $(17.85 \%)$ of the students claimed that working with the team contributes to the development of soft skills, such as responsibility and meeting deadlines: "Working in a team teaches you what responsibility and meeting deadlines mean and how important they are in teamwork" (questionnaire).

Over three quarters $(76.80 \%)$ of the students recognized that teamwork has a central contribution to the development of interdisciplinary lessons: "Teamwork is very important... it plays a great part in the development of the interdisciplinary lesson" (questionnaire). Approximately half $(48.20 \%)$ the students expressed an attitude, according to which in order to overcome the aforementioned difficulties, one needs to show flexibility and compromise: "You have to negotiate... the final product is a compromise... sometimes teamwork requires flexibility... you have to try seeing how the others see the whole picture" (interview).

Tables I shows the cognitive component of students' attitudes towards developing interdisciplinary lessons as part of heterogeneous teams. The frequency stated in the Table only refers to the frequency in which the findings arose in the questionnaire. In addition, the examples were taken from students' answers to the questionnaire.

\section{Discussion}

The study described in the paper followed students' attitudes towards developing interdisciplinary lessons in heterogeneous teams. The findings of the study indicate the presence of an affective component in students' attitudes, according to which working as a team reinforces the sense of self-confidence; the presence of a behavioral component, according to which while developing the lesson, team members tried to place more emphasis on the discipline they were familiar with at the expense of the fields of knowledge their teammates were familiar with; and the presence of a cognitive component, which relates both to the difficulties in teamwork and the advantages inherent to it. The main challenge pinpointed was the team members' difficulty in agreeing on an interdisciplinary topic, and the primary advantage found relates to the fact that the team contributes to the completion of knowledge gaps in various disciplines due to its heterogeneous composition. According to the results, the weight of the component which recognized the contribution teamwork made to developing the interdisciplinary lesson is considerably higher than that of the component pointing out the difficulties in teamwork. It is important to note that the finding that the students pointed out the difficulties accompanying teamwork is not surprising, since students generally find it hard to acclimatize to teamwork, which usually constitutes a new learning environment for them [24].

It is interesting to compare these findings to those related to the course's original format where the students did not work in teams, rather, each student developed and taught an interdisciplinary lesson on his/her own [14]. Those students found, similarly to what is stated in literature [12-13], that interdisciplinary teaching requires substantial resources, and that it presents a challenge due to the need to cope with new fields of knowledge, and because one needs to find a mix balancing the disciplinary and interdisciplinary elements. It was further found that during the interdisciplinary lessons, the students preferred to teach the field of knowledge they were familiar with at the expense of teaching disciplines that were new to them [14].

The components referring to the large investment of resources and the challenge involved in coping with new fields of knowledge do not appear in the findings of the current study. This may be assigned to working in heterogeneous teams, in which each team member was well versed in a different discipline, that assisted the students in mutually completing their knowledge gaps, without it being necessary to invest a great deal of resources. In addition, according the findings of the present study, teamwork contributed to finding a balanced mix between the lesson's disciplinary and interdisciplinary elements. It is interesting to note that the behavioral component in students' attitudes mentioned in the previous study, according to which students preferred to teach the discipline they were well versed in over the new fields of knowledge, was found to be present in the current study too, although with the necessary adjustment: while developing the lesson, team members tried to give the discipline they were familiar with greater weight at the expense of the fields of knowledge the other teammates were familiar with.

The theoretical contribution of the study is reflected in the characterization of science and engineering education students' attitudes towards developing interdisciplinary lessons in heterogeneous teams. To the best of our knowledge, this is the first time a characterization like this has been implemented. The practical contribution is likely to be expressed in the implementation of the findings 
PAPER

DEVELOPMENT OF INTERDISCIPLINARY LESSONS INTEGRATING SCIENCE AND ENGINEERING IN HETEROGENEOUS TEAM...

TABLE I.

DEVELOPING INTERDISCIPLINARY LESSONS IN HETEROGENEOUS TEAMS - STUDENTS’ ATTITUDES (COGNITIVE COMPONENT)

\begin{tabular}{|c|c|c|c|c|}
\hline Category & Sub-category & Frequency (\%) & Example & Interpretation \\
\hline \multirow{2}{*}{ Difficulties } & $\begin{array}{l}\text { Difficulty in choosing } \\
\text { an agreed upon inter- } \\
\text { disciplinary topic }\end{array}$ & 30.40 & $\begin{array}{l}\text { It [the process of developing the lesson] raises the difficul- } \\
\text { ty of choosing the topic [of the interdisciplinary lesson] in } \\
\text { a way which will integrate all of the team members' fields } \\
\text { of interest and knowledge. }\end{array}$ & $\begin{array}{l}\text { Difficulty in reaching agreement } \\
\text { within the team regarding the } \\
\text { interdisciplinary topic of the } \\
\text { lesson }\end{array}$ \\
\hline & \begin{tabular}{|l|} 
Difficulty in reaching \\
agreement in relation \\
to the content of the \\
interdisciplinary lesson \\
\end{tabular} & 24.10 & $\begin{array}{l}\text { It [the process of developing the lesson] raises disagree- } \\
\text { ments regarding the contents, the depth they will be dis- } \\
\text { cussed, and the order of their importance. }\end{array}$ & $\begin{array}{l}\text { Difficulty in reaching agreement } \\
\text { within the team regarding the } \\
\text { content of the interdisciplinary } \\
\text { lesson }\end{array}$ \\
\hline \multirow{4}{*}{ Advantages } & $\begin{array}{l}\text { Completion of } \\
\text { knowledge gaps }\end{array}$ & 62.50 & $\begin{array}{l}\text { It's good that each member of the team is well versed in } \\
\text { another field. I had knowledge gaps which A. noticed and } \\
\text { we discussed them together. }\end{array}$ & $\begin{array}{l}\text { Teamwork contributes to the } \\
\text { completion of knowledge gaps } \\
\text { among the team members }\end{array}$ \\
\hline & $\begin{array}{l}\text { Improving teaching } \\
\text { skills }\end{array}$ & 42.85 & $\begin{array}{l}\text { One can practice speaking in front of an audience [the } \\
\text { team members], and receive constructive criticism regard- } \\
\text { ing the content and the presentation, and that's how it } \\
\text { [teamwork] contributes to improving teaching skills. }\end{array}$ & $\begin{array}{l}\text { Teamwork contributes to improv- } \\
\text { ing the team members' teaching } \\
\text { skills }\end{array}$ \\
\hline & $\begin{array}{l}\text { Finding a balanced } \\
\text { mix between the } \\
\text { disciplinary and the } \\
\text { interdisciplinary } \\
\text { components } \\
\end{array}$ & 37.50 & $\begin{array}{l}\text { Teamwork helps in understanding how the lesson should } \\
\text { be structured, how much of the lesson should be interdis- } \\
\text { ciplinary and how much of it should be disciplinary. }\end{array}$ & $\begin{array}{l}\text { Teamwork contributes to finding } \\
\text { a balanced mix between the } \\
\text { disciplinary and the interdiscipli- } \\
\text { nary components of the lesson }\end{array}$ \\
\hline & Instilling soft skills & 17.85 & $\begin{array}{l}\text { It [working in a team] teaches you about responsibility } \\
\text { and meeting deadlines. }\end{array}$ & $\begin{array}{l}\text { Teamwork instills responsibility } \\
\text { and the ability to meet deadlines }\end{array}$ \\
\hline \multirow{2}{*}{ Insights } & $\begin{array}{l}\text { Major contribution to } \\
\text { the development of } \\
\text { interdisciplinary } \\
\text { lessons }\end{array}$ & 76.80 & $\begin{array}{l}\text { Teamwork is important; it contributes greatly to the de- } \\
\text { velopment of interdisciplinary lessons. }\end{array}$ & $\begin{array}{l}\text { Teamwork makes a major contri- } \\
\text { bution to the development of the } \\
\text { interdisciplinary lesson }\end{array}$ \\
\hline & $\begin{array}{l}\text { Need for mutual } \\
\text { consideration and } \\
\text { compromise }\end{array}$ & 48.20 & $\begin{array}{l}\text { The way to overcome the difficulties [choosing an agreed } \\
\text { upon interdisciplinary topic and reaching a decision about } \\
\text { the lesson's components] is by being attentive and consid- } \\
\text { erate of each other's wishes. }\end{array}$ & $\begin{array}{l}\text { Overcoming the difficulties } \\
\text { involved in teamwork requires } \\
\text { consideration and compromise }\end{array}$ \\
\hline
\end{tabular}

while developing interdisciplinary programs. This contribution is given new validity considering the expectation that interdisciplinary learning will develop higher-order thinking skills [2-3], and in view of the claim, according to which one of the primary conditions for the success of an interdisciplinary program is it being developed and taught by a heterogeneous team of teachers [12, 16-17].

The current study focused on students' attitudes towards developing an interdisciplinary lesson as part of a heterogeneous team. Informal conversations with the teaching faculty indicate that the course is interesting, although it is more time-consuming than regular courses. In a continuation study, we intend to examine the teachers' attitudes towards the course.

\section{CONCLUSIONS}

Considering that one of the most important conditions for the success of an interdisciplinary program is it being developed and taught by a heterogeneous team, the Department of Education in Technology and Science at the Technion - Israel Institute of Technology decided to train students in teamwork for the purpose of developing an interdisciplinary lesson integrating science and engineering. The current study examined students' attitudes towards developing an interdisciplinary lesson as part of a heterogeneous team. The findings indicate that the weight of the component which acknowledges the contribution of the work in teams to the development of interdisciplinary lessons is notably higher than the weight of the component indicating the difficulties involved in teamwork.

\section{REFERENCES}

[1] T. J. Klein, Interdisciplinarity: History, Theory and Practice, Detroit: Wayne State University Press, 1990.

[2] D. B. Ackerman and D. N. Perkins, "Integrating thinking and learning skills across the curriculum," in Interdisciplinary Curriculum: Design and implementation, H. H. Jacobs, Eds. VA: Association for Supervision and Curriculum Development, 1989, pp. $25-38$.

[3] M. Field, R. Lee, and M. L. Field, "Assessing interdisciplinary learning," New Directions for Teaching and Learning, vol. 58, pp. 69-84, 1994. http://dx.doi.org/10.1002/tl.37219945806

[4] L. R. Lattuca, L. J. Voight, and K. Q. Fath, "Does Interdisciplinarity promote learning? Theoretical support and researchable questions," The Review of Higher Education, vol. 28, pp. 23-48, 2004. http://dx.doi.org/10.1353/rhe.2004.0028

[5] A. Gero, "Interdisciplinary program on aviation weapon systems as a means of improving high school students' attitudes towards physics and engineering," International Journal of Engineering Education, vol. 29(4), pp. 1047-1054, 2013.

[6] A. Gero and E. Zach, "High school program in electro-optics: A case study on interdisciplinary learning and systems thinking," International Journal of Engineering Education, vol. 30(5), pp. 1190-1199, 2014.

[7] F. Zhou, P. Scott, and D. Talwar, "Multiple dimensional outreach activities attract students to the electro-optics program," in Proceedings of the 11th International Conference on Education and Training in Optics and Photonics, International Society for Optics and Photonics (SPIE), 2009. http://dx.doi.org/10.1117/12.2207937

[8] I. M. Verner and D. J. Ahlgren, "Fire-fighting robot contest: Interdisciplinary design curricula in college and high school," Journal of Engineering Education, vol. 91(3), pp. 355359, 2002. http://dx.doi.org/10.1002/j.2168-9830.2002.tb00715.x

[9] T. G. Ewers, "Idaho robotics opportunities for K-12 students: A $\mathrm{K}-12$ pipeline of activities promoting careers in science, engineering, and technology," Journal of Extension, vol. 48(1), Article 1IAW2, 2004. 
[10] J. A. Rursch, A. Luse, and D. Jacobson, "IT-adventures: A program to spark IT interest in high school students using inquirybased learning with cyber defense, game design, and robotics," IEEE Transactions on Education, vol. 53, pp. 71-79, 2010. http://dx.doi.org/10.1109/TE.2009.2024080

[11] H. G. Bagaria, M. R. Dean, C. A. Nichol, and M. S. Wong, "Selfassembly and nanotechnology: Real-time, hands-on, and safe experiments for K-12 students," Journal of Chemical Education, vol. 88(5), pp. 609-614, 2011. http://dx.doi.org/10.1021/ed100598y

[12] E. J. H. Spelt, H. J. A. Biemans, H. Tobi, P. A. Luning, and M. Mulder, "Teaching and learning in interdisciplinary higher education: A systematic review," Educational Psychology Review, vol. 21, pp. 365-378, 2009. http://dx.doi.org/10.1007\%2Fs10648009-9113-z

[13] W. McComas and H. Wang, "Blended science: The rewards and challenges of integrating the science disciplines for instruction," School Science and Mathematics, vol. 98(6), pp. 340-348, 1989. http://dx.doi.org/10.1111/j.1949-8594.1998.tb17430.x

[14] A. Gero, "Students' attitudes towards interdisciplinary education: A course on interdisciplinary aspects of science and engineering education," European Journal of Engineering Education, in press. http://dx.doi.org/10.1080/03043797.2016.1158789

[15] C. Woods, "Researching and developing interdisciplinary teaching: Towards a conceptual framework for classroom communication," Higher Education, vol. 54, pp. 853- 866, 2007. http://dx.doi.org/10.1007/s10734-006-9027-3

[16] M. B. Gilkey, and J. A. L. Earp, "Effective interdisciplinary training: Lessons from the University of North Carolina's Studen Health Action Coalition," Academic Medicine, vol. 81(8), pp. 749-758, 2006.

[17] J. K. Graybill, S. Dooling, V. Shandas, J. Withey, A. Greve, and G. L. Simon, "A rough guide to interdisciplinarity: Graduate student perspectives," Bioscience, vol. 56(9), pp. 757-763, 2006. http://dx.doi.org/10.1641/0006-3568(2006)56[757:ARGTIG]2.0.C $\mathrm{O} ; 2$

[18] P. L. Gardner, "The roots of technology and science: A philosophical and historical view," International Journal of Technology and Design Education, vol. 7, pp. 13-20, 1997. http://dx.doi.org/10.1023/A:1008892400827
[19] S. Waks, "Science-technology dimensions in physics education: Prospects and impact," Physics Education, vol. 29, pp. 64-70, 1994. http://dx.doi.org/10.1088/0031-9120/29/2/002

[20] J. Piaget, "The epistemology of interdisciplinary relationship," in Interdisciplinarity: Problems of Teaching and Research in Universities, L. Apostel, G. Berger, A. Briggs, and G. Michaud, Eds. Paris: OECD, 1972, pp. 127-139.

[21] S. Nikitina, "Three strategies for interdisciplinary teaching: Contextualizing, conceptualizing, and problem-centering, " Journal of Curriculum Studies, vol. 38(3), pp. 251-271, 2006. http://dx.doi.org/10.1080/00220270500422632

[22] M. Q. Patton, Qualitative Evaluation and Research Methods, CA: Sage Publications, 1990.

[23] M. J. Rosenberg and C. I. Hovland, "Cognitive, affective and behavioral components of attitudes," in Attitude Organization and Change: An Analysis of Consistency among Attitude Components, M. J. Rosenberg, C. I. Hovland, W. J. McGuire, R. P. Abelson, and J. W. Brehm, Eds. New-Haven: Yale University Press, 1964, pp. 1-14.

[24] L. E. George and R. B. Brown, "Engineering 100: An introduction to engineering systems at the US Air Force Academy," in Proceedings of the 2007 ASEE Annual Conference and Exposition, American Association of Engineering Education, 2007. http://dx.doi.org/10.1109/SYSOSE.2007.4304252

\section{AUTHOR}

A. Gero holds a B.A. in Physics, a B.Sc. in Electrical Engineering, an M.Sc. in Electrical Engineering, and a Ph.D. in Theoretical Physics, all from the Technion Israel Institute of Technology. In addition, he has an MBA from the University of Haifa, Israel. He is a faculty member at the Department of Education in Technology and Science of the Technion (gero@technion.ac.il). His research focuses on electrical engineering education and interdisciplinary education that combines physics with electronics, such as electro-optics and microelectronics education.

Submitted, 28 March 2016. Published as resubmitted by the author on 12 May 2016.

\section{APPENDICES}

\section{APPENDIX A: INTERDISCIPLINARY LESSONS}

Table II provides a sample of the interdisciplinary lessons developed as part of the course "Interdisciplinary Aspects in Science and Engineering Education". In addition to the lesson topic, the Table also specifies the disciplinary components.

TABLE II

INTERDISCIPLINARY LESSONS - TOPICS AND DISCIPLINARY COMPONENTS

\begin{tabular}{|l|l|l|}
\hline \multicolumn{1}{|c|}{ Lesson topic } & Science component & Engineering component \\
\hline Computers & Computer sciences & Electrical engineering \\
\hline Cranes & Physics & Mechanical engineering \\
\hline Hearing aids & Biology/Medicine & Electrical engineering \\
\hline Laser rangefinders & Physics & Electrical engineering \\
\hline $\begin{array}{l}\text { Microelectronics } \\
\text { processing }\end{array}$ & Chemistry & Electrical engineering \\
\hline $\begin{array}{l}\text { Optical communica- } \\
\text { tion }\end{array}$ & Physics & Electrical engineering \\
\hline Photovoltaic cells & Physics & Electrical engineering \\
\hline Prostheses & Biology/Medicine & Mechanical engineering \\
\hline $\begin{array}{l}\text { Sphygmomanome- } \\
\text { ters }\end{array}$ & Biology/Medicine & Mechanical engineering \\
\hline
\end{tabular}

\section{APPENDIX B: INTERDISCIPLINARY LESSON ON LASER RANGEFINDERS}

The university-level lesson dealing with laser rangefinders integrated physics and electrical engineering. The lesson started with a review of the Bohr model and a calculation of the energy levels of a hydrogen-like atom. This was followed by the description of the processes relevant to light-matter interaction, such as absorption, spontaneous emission, and stimulated emission. Later on, the basic operating principles of the laser were explained, and the properties of laser light, such as monochromaticy, coherence, and directionality were discussed, as well as the difference between a continuous-wave laser and a pulse laser. This was followed by a description of the structure and the working principle of a laser rangefinder, and a discussion was held about the factors influencing the accuracy of the measurement. The lesson was ended with a review of some civilian and military applications.

\section{APPENDIX C: OPEN-ENDED QUESTIONNAIRE}

Following is the open-ended questionnaire mentioned in Section III:

- Describe your work during the lesson development stage.

- What did you learn from the process of developing an interdisciplinary lesson as part of a team? 
DEVELOPMENT OF INTERDISCIPLINARY LESSONS INTEGRATING SCIENCE AND ENGINEERING IN HETEROGENEOUS TEAM...

\section{APPENDIX D: INTERVIEW QUESTIONS}

Following is a sample of questions from the interview mentioned in Section III:

- What do you think about the experience of developing an interdisciplinary lesson? Explain.

- Describe your work during the development stage. Describe your feelings.

- What was the best thing about teamwork? Explain.

- What was the worst thing about teamwork? Explain.

- What did you learn from the experience of developing an interdisciplinary lesson as part of a team? 